\title{
The Rise and Fall of Industrial Research Labs
}

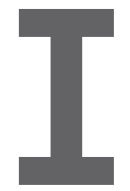

SPENT SOME of my most formative years as a researcher at the IBM Almaden Research Center. Those were magical years. IBM Research was then a Camelot of computing research, with the motto of being "Famous for its science, and vital to IBM for its technology." IBM researchers received Nobel prizes for their discoveries of high-temperature superconductivity and the scanning tunneling microscope. IBM researchers invented the magnetic disk drive and relational databases. As a young researcher, I could not ask for a better research environment.

But the economic recession of the early 1990s hit IBM very hard, and the stress was acutely felt inside the Research Division. From an equal emphasis on science and technology, the balance was shifting more and more toward technology. When IBM reported its financial results in October 1992, its worst-ever quarterly loss of close to $\$ 3$ billion shook the corporation to its core. IBM's CEO, John Akers, resigned in January 1993, and Louis Gerstner arrived as new CEO in April 1993, embarking on his storied transformation of IBM. The Research Division never fully recovered from the trauma of the early 1990s. Just as IBM lost the leadership of the computing world, passing the mantle to Cisco, Intel, and Microsoft, IBM Research lost the leadership of computing research. A mass exodus of talent took place throughout the 1990s. (I resigned in 1995.) IBM Research today is still a powerhouse of talent, with occasional outstanding research accomplishments, for example, Deep Blue and Watson; its main focus, however, is on supporting the nearterm business of IBM's business units. The mantle of computing-research leadership passed to Microsoft Research, with close to 1,000 researchers and many research labs all over the world.

I was acutely reminded of those challenging times in the 1990s, when the news flashed last September that Microsoft Research closed down its Silicon Valley Lab, laying off dozens of researchers. Of course, Microsoft's business challenges have been a topic of wide public discussion for the past few years, and the lab closure was part of a major strategy shift in Microsoft, which included layoffs of 18,000 employees. Yet, the swiftness of the lab closure, and the fact that Microsoft decided to close a lab located in Silicon Valley, widely considered the mecca of computing, shook the computingresearch community.

This sense of nasty surprise led to an unusual public exchange of letters in October. Some 28 members of the theoretical computer science community posted an open letter to Microsoft Research management, expressing “the research community's shock and disappointment at the sudden and harsh way in which the members of the Microsoft Research Silicon Valley Lab were dismissed," and calling for "a dialogue about the ways in which Microsoft can try to restore the environment that enabled MSR to produce such great research in the past." Microsoft Research's management issued a response within a week, explaining the closure of the lab as a business necessity, and stating Microsoft's continued commitment to fundamental research. (See story on the Computing Research Association's Computing Policy Blog, http://bit.ly/1xcVxKe/.)

While the specifics of Microsoft Research's actions may have been surprising, these actions are entirely con- sistent with the historical pattern of the rise and fall of industrial research labs. While the rise and fall of IBM Research is discussed above, other research labs, such as Bell Labs, Xerox Palo Alto Research Center, and DEC's Research Labs, went through similar phases. The technology business is conducive to a "winner-takes-all" pattern; whereby an early entrant develops a technology niche and goes on to dominate it, establishing an effective monopoly. Dominant corporations can afford to establish research divisions that focus not only on research that is directly relevant to the corporation's business, but also on research of broader scope and longer term. Inevitably, however, the business environment changes, dominance is lost, and emphasis on research yields to more pressing business needs.

Microsoft Research after the closure of the Silicon Valley Lab is a changed place. Once a sense of invincibility is lost, it simply cannot be regained. The decision to close a single lab and lay off most of its researchers-including many top performers-rather than spread the pain across the whole research division, whatever its business rationale (which I cannot judge), means that Microsoft researchers are now acutely aware of their vulnerability. This sense of vulnerability may have serious consequences. Ultimately, the future of Microsoft Research is intimately tied to the future of Microsoft itself. Can Microsoft retain its dominance? Can Microsoft Research retain its commitment to fundamental research?

Follow me on Facebook, Google+, and Twitter.

\footnotetext{
Moshe Y. Vardi, EDITOR-IN-CHIE F

Copyright held by author.
} 